\title{
Increase in physical activity is associated with lower HbA1c levels in children and adolescents with type 1 diabetes: results from a cross- sectional study based on the Swedish pediatric diabetes quality registry (SWEDIABKIDS)
}

\author{
Å Beraki, A. Magnuson, S. Särnblad, J. Åman and Ulf Samuelsson
}

Linköping University Post Print

\section{Tweet}

N.B.: When citing this work, cite the original article.

Original Publication:

Å Beraki, A. Magnuson, S. Särnblad, J. Åman and Ulf Samuelsson, Increase in physical activity is associated with lower HbA1c levels in children and adolescents with type 1 diabetes: results from a cross-sectional study based on the Swedish pediatric diabetes quality registry (SWEDIABKIDS), 2014, Diabetes Research and Clinical Practice, (105), 1, 119-125.

http://dx.doi.org/10.1016/j.diabres.2014.01.029

Copyright: Elsevier

http://www.elsevier.com/

Postprint available at: Linköping University Electronic Press http://urn.kb.se/resolve?urn=urn:nbn:se:liu:diva-109230 
Increase in physical activity is associated with lower HbA1c levels in children and adolescents with type 1 diabetes: results from a cross-sectional study based on the Swedish pediatric diabetes quality registry (SWEDIABKIDS).

Authors: Å Beraki, medical student, Linköping University, Linköping, Sweden.

A Magnuson, BSc, Clinical epidemiology and biostatistic unit, Örebro University Hospital, Örebro, Sweden.

S Särnblad, MD, PhD, Department of Pediatrics, Örebro University Hospital, Department of Health and Clinical Science, Örebro University, Örebro, Sweden.

J Åman, MD, PhD, Department of Pediatrics, Örebro University Hospital, Department of Health and Clinical Science, Örebro University, Örebro, Sweden.

U Samuelsson, MD, PhD, Department of Clinical and Experimental Medicine, Division of Pediatrics and Diabetes research centre, Linköping University Hospital, Linköping, Sweden.

Word count: 4740

Corresponding author: Ulf Samuelsson

Department of Clinical and Experimental Medicine, Division of Pediatrics and Diabetes research centre, Linköping University Hospital, Linköping, S-581 85 Sweden.

Phone: +46101030000

Fax: +4613148265

Mail: ulf.samuelsson@lio.se 


\section{Abstract}

Aims: To evaluate the associations between physical activity (PA) and metabolic control, measured by glycosylated hemoglobin (HbA1c), in a large group of children and adolescents with type 1 diabetes.

Methods: Cross-sectional analysis of data from 4,655 patients, comparing HbA1c values with levels of physical activity. The data for the children and adolescents were obtained from the Swedish pediatric diabetes quality registry, SWEDIABKIDS. The patients were 7-18 years of age, had type 1 diabetes and were not in remission. Patients were grouped into five groups by frequency of PA.

Results: Mean HbA1c level was higher in the least physically active groups (PA0: $8.8 \% \pm 1.5$ $(72 \pm 16 \mathrm{mmol} / \mathrm{mol}))$ than in the most physically active groups (PA4: 7.7\% $\pm 1.0(60 \pm 11$ $\mathrm{mmol} / \mathrm{mol}))(\mathrm{p}<0.001)$. An inverse dose-response association was found between PA and HbA1c $(\beta$ : $-0.30,95 \%$ CI: $-0,34$ to $-0,26, p<0.001)$. This association was found in both sexes and all age groups, apart from girls aged 7-10 years. Multiple regression analysis revealed that the relationship remained significant $(\beta:-0.21,95 \% \mathrm{CI}:-0.25$ to $-0.18, \mathrm{p}<0.001)$ when adjusted for possible confounding factors.

Conclusions: Physical activity seems to influence HbA1c levels in children and adolescents with type 1 diabetes. In clinical practice these patients should be recommended daily physical activity as part of their treatment.

Key words: HbAlc, physical activity, metabolic control, quality register 


\section{Introduction}

Physical activity has an important part to play in the prevention of diabetes complications and in the management of type 1 and type 2 diabetes mellitus $(1,2)$. To attain desired health outcomes, school-age youth are recommended to engage in moderate to vigorous physical activity 60 minutes or more per day (3). Swedish guidelines for diabetes care recommend regular physical activity for patients with type 1 diabetes (4). Physical activity benefits the lipid profile and blood pressure (1), and improves endothelial function (2) all of which are of great value in reducing diabetes-related complications such as cardiovascular disease.

Furthermore, physical activity increases insulin sensitivity, improves physical fitness and increases psychological well-being in patients with type 1 diabetes (2).

Another possible health benefit of physical activity is better metabolic control, with reduced glycosylated hemoglobin (HbA1c). Several studies have focused on the correlation between physical activity and HbA1c. Some have succeeded in showing a significant HbA1c-lowering effect of physical activity (5-15), whereas others have failed do so (16-22). HbA1c is a main variable in pediatric diabetes care. Prospective randomized trials suggest a strong, exponential association between high long-standing HbA1c levels and increased risk of diabetic microangiopathy (23)

The aim of the present study is to evaluate associations between physical activity and metabolic control, measured by HbA1c values, in children and adolescents with type 1 diabetes in Sweden.

\section{Material and Methods}

The Swedish pediatric diabetes quality registry 
Outpatient attendance data from all Swedish pediatric diabetes centers $(n=43)$ are registered in the Swedish pediatric diabetes quality registry, SWEDIABKIDS (24), which was set up in 2000. In Sweden, pediatric clinics treat all children and adolescents aged 0-18 years with diabetes from defined geographic areas. Thus the registry includes data on almost all (around $99 \%$ ) of the children and adolescents with diabetes in Sweden. In 2010, the registry included data from more than 235,000 outpatient visits. There are no data on the ethnic origin of individual children in SWEDIABKIDS as Swedish legislation prohibits the registration of such data. From an ongoing study, however, in which the registry is linked to other registries, it is known that only $6.8 \%$ of children with type 1 diabetes in Sweden have two parents originating from outside the country.

From 2000 to 2007, data were registered locally in a specially designed program for childhood diabetes. The registry has been web-based since 2008 and is available to all pediatric diabetes centers in Sweden. SWEDIABKIDS is financially supported by the Association of Local Authorities and Regions, SALAR, which represents the governmental, professional and employer-related interests of Sweden's municipalities, county councils and regions (25). SWEDIABKIDS has the status of a national quality registry. On being diagnosed with diabetes, patients are informed by the diabetes team about the registry and that the clinical variables in the registry may be used for research after approval by an ethics committee. Patient consent is then requested. The study protocol was approved by the regional ethics committee in Uppsala, Sweden.

\section{Methods}

All laboratory methods used in Sweden are standardized through EQUALIS (External Quality Assurance in Laboratory Medicine in Sweden). The data on HbA1c obtained from SWEDIABKIDS were derived from capillary blood samples measured with the 
Bayer/Siemens DCA-2000 analyzer (Erlangen, Germany) or using local laboratory methods (high-performance liquid chromatography) (26). HbA1c values will be presented in NGSP units $(\%)$, followed by IFFC units ( $\mathrm{mmol} / \mathrm{mol})$ within parentheses: $58 \mathrm{mmol} / \mathrm{mol}$ (IFCC) corresponds to $7.5 \%$ (NGSP), whereas $10 \mathrm{mmol} / \mathrm{mol}$ is approximately $0.9 \%$ (27).

\section{Material}

According to Swedish guidelines, children with diabetes visit the diabetes center at least four times/year up to 18 years of age (28). At these visits HbA1c and other clinical variables such as insulin dose, weight, and height are measured. Data on BMI and BMI-SDS are calculated (29). Weight and height are measured by the nurses in the diabetes team. The patients also report severe hypoglycemic episodes (defined as requiring assistance from another person, occurrence of seizure or loss of consciousness) and diabetic ketoacidosis, and how frequently they participate in physical activity on a weekly basis. Data on physical activity are registered for children and adolescents older than 7 years of age. To ensure that the registry is as reliable as possible the patients are actively asked by the members of the diabetes team about hypoglycemic episodes, and the type and duration of the physical activity they have engaged in.

In the present study we grouped the patients by frequency of physical activity lasting at least 30 minutes each occasion as follows: PA0, none, PA1, less than once a week, PA2, 1-2 times per week, PA3, 3-5 times per week, and PA4, every day. The definition of at least 30 minutes of physical activity leading to breathlessness has been used in The Health Behaviour in School-aged Children Questionnaires by WHO in healthy children conducted in 3-year cycles in over 30 countries (30) and by the international Hvidoere Study Group on Childhood Diabetes (18)

We have limited our material to include data from 2010-2011 only. Within that time period, SWEDIABKIDS contains data on 7,144 children and adolescents, 7-18 years old, with type 1 
diabetes and a total of 43,612 visits. In the present study we included only visits where HbA1c had been registered. We excluded patients who are likely to be in remission (insulin dose $<0.5$ units per kilogram per day and/or disease duration of less than one year). From this defined study population $(n=6,483$, visits $=34,618)$, we selected all children and adolescents for whom physical activity had been registered, i.e. $72 \%$ of the patients. Thus for $28 \%$ of the patients in the registry, physical activity is not registered. Data on 4,655 children and adolescents and a total of 16,891 visits remained after the above exclusions. The number of visits per patient within the defined time period varied between 1 and 27 (median: 5).

So that patients with a high number of visits would not have too great an impact on the association, we decided that each individual should only contribute once to the analyses. In line with this decision, mean $\mathrm{HbA1c}$ was used to summarize each patient level of $\mathrm{HbA} 1 \mathrm{c}$ and mean PA were used to summarize level of PA. Mean were also used to summarize other continuously measured factors such as age, disease duration, insulin dose and BMI-SDS. Insulin methods were summarized for each patient as injection at all visits, pump at all visits or both methods used. Episode of severe hypoglycemia the past month and smoking habits were summarized in a similar way. The clinical data from these 4,655 patient visits were analyzed in the present study. The study population was stratified by gender and age in the following age groups: $7-10,11-14$, and 15-18. For comparison, we summarized in the same way the remaining patients for whom physical activity had not been registered at any of their visits.

\section{Statistical analyses}

Linear regression was used to evaluate the association between mean level of physical activity and mean of HbA1c (according to IFCC), with physical activity measured as a linear association of HbA1c. Unadjusted regression analyses were performed on the whole dataset as well as stratified by sex and age groups. We also performed regression analyses adjusted 
for gender and mean age, and for other potential confounding factors that were statistically significantly associated to physical activity (Table 1) as well as number of visits. Due to only $<1 \%$ smokers among patients younger than 15 years we only adjusted for smoking habits when analyzing age group 15-18 years All variables were analyzed on a categorical scale apart from physical activity and insulin dose, which was analyzed on a linear scale.

The patients were divided by disease duration into $<5$ years and $>5$ years. In table 1 and figure 1 mean PA were categorized to PA0, PA1, PA2, PA3 and PA4 and one-way ANOVA was used to compare continuously measured variables between PA0-PA4 and chi-squared test was used to compare categorical variables

Longitudinal relation between change in mean PA and mean HbA1c from year 2010 to 2011 was evaluated. Mean PA and mean HbA1c was summarized for each year and patient and change in PA was categorized; increased PA level by more than one category of PA, decreased PA by more than one category or unchanged level of PA (reference). Linear regression was applied with mean HbA1c in 2011 as outcome, mean HbA1c in 2010 and PA change as independent variables, the latter evaluated as a categorical variable, as well as adjusting for mean age and sex.

A p value $<0.05$ or $95 \%$ confidence interval not including 0 was considered statistically significant. All statistics were analyzed using SPSS, version 21 (SPSS Inc, IBM Corporation, Somers, NY, USA).

\section{Results}

\section{Clinical characteristics}

Data from 4,655 visits were included in the analysis. The mean age of the patients was $14.3 \pm$ 3.1 years with a median diabetes duration of 5.7 years $(1.0-17.7 . y)$ and a mean HbA1c of 8.1 $\pm 1.2(65 \pm 13 \mathrm{mmol} / \mathrm{mol})$. When the data were stratified by gender and age, we found that the 
HbA1c level increased with increasing age. Furthermore, girls in age group 15-18 y had 0.30 $\%(3.3 \mathrm{mmol} / \mathrm{mol})$ higher HbA1c than boys in the same age group $(\mathrm{p}<0.001)$. In the other age groups, there was no statistically significant gender difference. The majority (49\%) of the children and adolescents were between 15 and 18 years of age (18\% aged 7-10, 33\% aged 11-14). The clinical characteristics are presented in Table 1.

\section{Level of physical activity}

Mean physical activity of 1-2 times per week (PA2) or more was reported by $89 \%$ of the subjects and 3-5 times /week (PA3) or more by 56\%. Lower physical activity was reported more by older children and adolescents ( $\mathrm{p}<0.001$ ), the mean age varying from 13.3 years in PA4 to 16.3years in PA0.

The boys were slightly more active than the girls, with $58 \%$ of the boys in PA3-PA4, compared with $53 \%$ of the girls $(\mathrm{p}<0.001)$. Disease duration was one year longer in the group with the lowest physical activity level than in the group with the highest level of physical activity, 6.5 and 5.2 years, respectively, $(\mathrm{p}<0.001)$. There was no statistically significant difference in BMI-SDS, but the number of smokers differed between the various physical activity groups. Among the patients in PA0, $19 \%$ were reported to use cigarettes at all visits compared with $1 \%$ in PA4 $(\mathrm{p}<0.001)$. Data on smoking habits were not reported for $33 \%$ of the patients analyzed, mainly by younger patients.

Association between physical activity and HbAlc

The mean HbA1c differed between the groups with different physical activity levels, as shown in Table 1. We found a higher HbA1c level in the groups that were least physically active (PA0: $8.8 \% \pm 1.5(72 \mathrm{mmol} / \mathrm{mol} \pm 16))$, compared with the more physically active groups (PA4: $7.7 \% \pm 1.0(60 \mathrm{mmol} / \mathrm{mol} \pm 11))(\mathrm{p}<0.001)$. The association between physical activity and HbA1c was statistically significant after adjustment for age and gender, with a mean decrease of HbA1c with a $\beta$-coefficient -0.26 (95\% CI: -0.29 to -0.22 ) for one unit 
increase of physical activity. After adjustment for disease duration, insulin dose, insulin method, hypoglycemia and number of visits, the association was still statistically significant with $\beta$-coefficient changed to -0.21 (95\% CI: -0.25 to -0.18$)$ (Table 2).

The linear regression showed statistically significant association in all groups, except the youngest girls aged 7-10 years, where no statistically significant association was found (girls; $\beta-0.07$ (95\% CI: -0.17 to $0.03, p=0.15$ in the adjusted model(Figure 1 ).

The longitudinal analyses showed a statistically significant relation between 2010 and 2011 , patients with increased PA improved HbA1c $(\beta=-0.14 ; p=0.002)$ compared to patients with unchanged level of PA. Patients with decreased PA increased their HbA1c $(\beta=0.16 ; p$ $=0.001)$ compared to patients with unchanged level of PA Association between physical activity and insulin treatment The data showed a decline in insulin dose when comparing the least active (1.00 IU/kg per day) with the most active group (0.91 IU/kg per day) ( $p<0.001)$. Severe hypoglycemic episodes were more frequent among the most physically active patients $(p=0.005)$. Comparison between groups with data on PA and those without data on PA Table 1 shows that the patients for whom PA had been registered are similar in terms of age and gender to the patients with no physical activity registered. Moreover, their mean HbAlc values are the same $(8.1 \pm 1.1 \%(65 \pm 12 \mathrm{mmol} / \mathrm{mol})$ in both groups $)$ (Table 1$)$. 


\section{Discussion}

Our population-based study of data from 4,655 children and adolescents with type 1 diabetes in the Swedish quality registry demonstrates a statistically significant inverse dose-response association between the amount of physical activity and HbA1c. Our results indicate significant associations between physical activity and $\mathrm{HbA1c}$ levels in patients with type 1 diabetes. This association could be explained by increased insulin sensitivity and improved glucose uptake in muscles, reflected by a reduced need for insulin and a lower HbA1c level in active adolescents with diabetes. Physical activity is also associated with increased healthrelated quality of life (31), which probably makes it easier for the patients to manage their diabetes. This effect was found in both sexes in all age groups but the youngest girls, 7-10 years of age. Among the youngest boys there was a statistically significant association, although it was much weaker than in the older age groups. The findings in the youngest age group might suggest that physical activity has a less HbA1c-lowering effect in this group. This may be due to the already rather low HbA1c values obtained in this young group or to methodological difficulties in differentiating PA from spontaneous play.

Most of the previous publications supporting an association between PA and HbA1c have been cross-sectional studies based on questionnaires, whereas the studies that failed to demonstrate a correlation mainly were intervention studies, assessing either the effect of an exercise program on $\mathrm{HbA} 1 \mathrm{c}$ level during a defined time period or the amount of physical activity participants engaged in over a few days measured with an accelerometer. The use of different methods of assessing PA and/or small study populations might explain the conflicting results. One of the studies that revealed a statistically significant correlation between physical activity and HbA1c is a large German cross-sectional questionnaire study (6). 
We are aware that the use of self-report questionnaires is not optimal (32) and that our results therefore need to be verified by objective methods. The registry and the different diabetes teams try, however, to make the measurements more reliable by actively asking the patients about the self-reported data. Another limitation of this study is the lack of information about the ethnic background of individual patients. We are aware, however, that the frequency of children with type 1 diabetes of non-Swedish origin is low. The registry also lacks data about the frequency of SMBG, which has recently been shown to be strongly associated with HbA1c (33). The strength of our study, however, is the large population-based population and a longitudinal analysis of associations between changes in PA and HbA1c.

There is also a discrepancy in terms of how the different diabetes centers have reported the data on physical activity. For $28 \%$ of the children, physical activity was not registered. As this is a substantial fall-off, we decided to include a 'PA unknown' category in our presentation to compare our results with the data from the part of the study population for whom physical activity had not been registered. As the results showed, the two groups have similar clinical characteristics and the same mean HbA1c value. It is, therefore, reasonable to suggest that our results are applicable to the entire study population.

As shown in Fig. 1 the declining trend in HbA1c level with each level of higher physical activity was not evident between PA0 and PA1. One reason for this result in the stratified analysis could be the low number of patients included in PA0 and PA1. Another reason might be the way these groups are categorized: PA0, none; PA1, less than once a week. The groups are quite similar and could well be grouped together in our opinion. However, we chose this categorization in the present study as it is the categorization used in the registry. The children and adolescents who reported a higher level of PA also reported a higher number of severe hypoglycemic episodes. This suggests that pediatric diabetes care should include 
knowledge of how to adjust food intake and insulin dose in relation to PA and promote the use of self-monitoring of blood glucose to avoid high and low blood glucose levels.

We have identified a risk group in terms of diabetes complications that might require special attention from diabetes treatment professionals. This group has a higher mean $\mathrm{HbA1c}$ level and includes a high proportion of children and adolescents who are smokers and physically active to a very low degree.

We believe that more studies with objective methods in large populations are required to validate or refute the inverse dose-response relationship between physical activity and HbA1c. Nevertheless, our study indicates that a higher level of physical activity is associated with better metabolic control. Physical activity should be recommended for all patients with type 1 diabetes and our exercise promotional tools in the clinic should be focused on female adolescents with a long disease duration who seems to be less active group.

\section{Acknowledgements}

The Swedish board of Health and Welfare, the Swedish Association of Local Authorities and Regions.

We thank the pediatric diabetes centers who have contributed to the study by registering data on the children and adolescents with type 1 diabetes attending their diabetes center.

No author has any conflicts of interest to declare. 


\section{References}

1. Zinman B, Ruderman N, Campaigne BN, Devlin JT, Schneider SH; American Diabetes Association. Physical activity/exercise and diabetes mellitus. Diabetes care, 2003; $26: 73-77$.

2. Chimen M, Kennedy A, Nirantharakumar K, Pang TT, Andrews R, Narendran P. What are the health benefits of physical activity in type 1 diabetes mellitus? A literature review. Diabetologia, 2012; 55: 542-551.

3. Strong WB, Malina RM, Blimkie CJ, Daniles SR, Dishman RK, Gutin B, et al. Evidence based physical activity for school-age youth. J Pediatr., 2005; 146: 732-737.

4. Adolfsson P. Motion, sport och idrott. In: Sjöblad S, editor. Barn- och ungdomsdiabetes. 2nd ed. Lund, Studentlitteratur; 2008.

5. Miculis CP, Mascarenhas LP, Boguszewski MCS, De Campos W. Physical activity in children with type 1 diabetes. J Pediatr (Rio J), 2010; 86: 271-278.

6. Herbst A, Bachran R, Kapellen T, Holl RW. Effects of regular physical activity on control of glycemia in pediatric patients with type 1 diabetes mellitus. Arch Pediatr Adolesc Med, 2006; 160: 573-577.

7. Robertson K, Adolfsson P, Riddell M, Scheiner G, Hanas R. Exercise in children and adolescents with diabetes. Pediatr Diabetes, 2009; 10 (Suppl.12): 154-168.

8. Williams BK, Guelfi KJ, Jones TW, Davis EA. Lower cardiorespiratory fitness in children with Type 1 diabetes. Diabet Med, 2011; 28: 1005-1007.

9. Bernardini AL, Vanelli M, Chiari G, Iovane B, Gelmetti C, Vitale R, et al. Adherence to physical activity in young people with Type 1 diabetes. Acta Biomed, 2004; 75: 153-157.

10. Schweiger B, Klingensmith G, Snell-Bergeon JK. Physical activity in adolescent females with type 1 diabetes. International Journal of Pediatrics, 2010; 2010: 328318. 
11. Salvatoni A, Cardani R, Biasoli R, Salmaso M, De Paoli A, Nespoli L. Physical activity and diabetes. Acta Biomed, 2005; 76: 85-88.

12. Michaliszyn SF, Faulkner MS. Physical activity and sedentary behaviour in adolescents with type 1 diabetes. Res Nurs Health, 2010; 33: 441-449.

13. Valerio G, Spagnuolo MI, Lombardi F, Spadaro R, Siano M, Franzese A. Physical activity and sports participation in children and adolescents with type 1 diabetes mellitus. Nutr Metab Cardiovasc Dis, 2005; 17: 376-382.

14. Zoppini G, Carlini M, Muggeo M. Self-reported exercise and quality of life in young type 1 diabetic subjects. Diabetes Nutrition \& Metabolism, 2003; 16: 77-80.

15. Sideraviciute S, Gailiuniene A, Visagurskiene K, Vizabaraite D. The effect of longterm swimming program on glycemia control in 14-19-year aged healthy girls and girls with type 1 diabetes mellitus. Medicina (Kaunas), 2006; 42: 513-518.

16. Roberts L, Jones TW, Fournier PA. Exercise training and glycemic control in adolescents with poorly controlled type 1 diabetes mellitus. J Pediatr Endocrinol Metab, 2002; 15: 621-627.

17. Särnblad S, Ekelund U, Åman J. Physical activity and energy intake in adolescent girls with Type 1 diabetes. Diabet Med, 2005; 22: 893-899.

18. Åman J, Skinner TC, De Beaufort CE, Swift PGF, Aanstoot H-J, Cameron F. Associations between physical activity, sedentary behaviour, and glycemic control in a large cohort of adolescents with type 1 diabetes: the Hvidoere Study Group on Childhood Diabetes. Pediatr Diabetes, 2009; 10: 234-239.

19. Edmunds S, Roche D, Stratton G. Levels and patterns of physical activity in children and adolescents with type 1 diabetes and associated metabolic and physiologic health outcomes. J Phys Act Health, 2010; 7: 68-77. 
20. Wallberg-Henriksson H, Gunnarsson R, Henriksson J, Defronzo R, Felig P, Östman J, et al. Increased peripheral insulin sensitivity and muscle mitochondrial enzymes but unchanged blood glucose control in type 1 diabetics after physical training. Diabetes, 1982; 31: 1044-1050.

21. Raile K, Kapellen T, Schweiger A, Hunkert F, Nietzschmann U, Dost A, et al. Physical activity and competitive sports in children and adolescents with type 1 diabetes. Diabetes care, 1999; 22: 1904-1905.

22. Lehman R, Kaplan V, Bingisser R, Bloch KE, Spinas GA. Impact of physical activity on cardiovascular risk factors in IDDM. Diabetes care, 1997; 20: 1603-1611.

23. The DCCT Research Group. Effect of intensive diabetes treatment on the development and progression of long-term complications in adolescents with insulin-dependent diabetes mellitus: Diabetes Control and Complications Trial. J Pediatr, 1994;125:17788.

24. Samuelsson U, SWEDIABKIDS. National quality registry for diabetes in children 018 years, Diabetes center, Gothenburg, Sweden [registry online], 2009. Available at https://www.ndr.nu/ndr2

25. Swedish association of local authorities and regions. Available at https://http://english.skl.se/ Accessed 10 January 2012

26. Jeppsson JO, Jerntorp P, Sundkvist G, Englund H, Nylund V. Measurement of hemoglobin A1c by a new liquid-chromatographic assay: methodology, clinical utility, and relation to glucose tolerance evaluated. Clin Chem, 1986; 32: 1867-1872.

27. Hanas R, John G. 2010 consensus statement on the worldwide standardization of the hemoglobin A1C measurement. Diabetes Care, 2010; 33(8): 1903-1904.

28. Örtqvist E, Forsander G, Sjöblad S. Diabetesmottagningens organisation. In: Sjöblad S, editor. Barn- och ungdomsdiabetes. 2nd ed. Lund, Studentlitteratur; 2008. 
29. Karlberg J, Luo ZC, Albertsson-Wikland K. Body mass index reference values (mean and SD) for Swedish children. Acta Paediat,r 2001; 90: 1427-1434.

30. Currie C, Hurrelman K, Settertobulte W, Smith R, Todd J. Health and behaviour among young people: Health Behaviour in School aged children: a WHO Cross National Study (HBSC) international report. Denmark: WHO Regional Office for Europe, 2000.

31. Gopenath B, Hardy LL, Baur LA, Burlutsky G, Michell P. Physical activity and sedentary behaviors and health-related quality of life in adolescents. Pediatrics, 2012; 130(1): 167-174.

32. Ekelund U, Tomkinson GR, Armstrong N. What proportion of youth are physically active? Measurement issues, levels and recent time trends. Br J Sports Med, 2011; 45: 859-865.

33. Miller KM, Beck RW, Bergenstal RM, Goland RS, Haller MJ, McGill JB, Rodriguez H, Simmons JH, Hirsch IB; for the T1D Exchange Clinic Network. Evidence of a Strong Association Between Frequency of Self-Monitoring of Blood Glucose and Hemoglobin A1C Levels in T1D Exchange Clinic Registry Participants. Diabetes Care. 2013 Feb 1. [Epub ahead of print] 
Table 1.

Characteristics of patients with type 1 diabetes stratified by frequency of physical activity Categorization of mean PA

\begin{tabular}{|c|c|c|c|c|c|c|c|c|}
\hline & $\begin{array}{c}\text { PAO } \\
(0-<0.5)\end{array}$ & $\begin{array}{c}\text { PA1 } \\
(0.5-<1.5)\end{array}$ & $\begin{array}{c}\text { PA2 } \\
(1.5-<2.5)\end{array}$ & $\begin{array}{c}\text { PA3 } \\
(2.5-<3.5)\end{array}$ & $\begin{array}{c}\text { PA4 } \\
(3.5-4) \\
\end{array}$ & $\mathbf{P}^{1}$ & Total & $\begin{array}{c}\text { PA } \\
\text { unknown }\end{array}$ \\
\hline $\begin{array}{l}\text { Number of } \\
\text { children }\end{array}$ & 158 & 371 & 1522 & 2009 & 595 & & 4655 & 1828 \\
\hline $\begin{array}{l}\text { Gender } \\
\text { Girls, \% }\end{array}$ & $44 \%$ & $44 \%$ & $50 \%$ & $45 \%$ & $39 \%$ & $<0.001$ & $46 \%$ & $46 \%$ \\
\hline $\begin{array}{l}\text { Age, y } \\
\text { Mean } \pm \text { SD }\end{array}$ & $16.3 \pm 2.2$ & $15.6 \pm 2.6$ & $14.5 \pm 3.1$ & $14.0 \pm 3.0$ & $13.3 \pm 3.6$ & $<0.001$ & $14.3 \pm 3.1$ & $14.0 \pm 3.7$ \\
\hline $\begin{array}{l}\text { Disease } \\
\text { Duration, y } \\
\text { Median } \\
\text { (range) } \\
\text { Insulin Dose, } \\
\text { IU/kg per d } \\
\text { Mean } \pm \text { SD }\end{array}$ & $\begin{array}{c}6.5 \\
(1.0-17.1) \\
\\
1.00 \pm 0.3\end{array}$ & $\begin{array}{c}6.9 \\
(1.0-17.4) \\
\\
1.01 \pm 0.5\end{array}$ & $\begin{array}{c}5.8 \\
(1.0-17.5)\end{array}$ & $\begin{array}{c}5.5 \\
(1.0-17.7)\end{array}$ & $\begin{array}{c}5.2 \\
(1.0-17.3)\end{array}$ & $<0.001$ & $\begin{array}{c}5.7 \\
(1.0-17.7) \\
\\
0.95 \pm 0.3\end{array}$ & $\begin{array}{c}5.3 \\
(1.0-18.7) \\
\\
0.96 \pm 0.3\end{array}$ \\
\hline $\begin{array}{l}\text { BMI-SDS, } \mathbf{k g} / \mathbf{m} \\
\text { Mean } \pm \text { SD } \\
\text { Missing, } \%\end{array}$ & $\begin{array}{c}0.59 \pm 1.4 \\
18 \%\end{array}$ & $\begin{array}{c}0.68 \pm 1.3 \\
9 \%\end{array}$ & $\begin{array}{c}0.70 \pm 1.1 \\
8 \%\end{array}$ & $\begin{array}{c}0.65 \pm 1.0 \\
6 \%\end{array}$ & $\begin{array}{c}0.64 \pm 1.0 \\
6 \%\end{array}$ & 0.536 & $\begin{array}{c}0.66 \pm 1.1 \\
7 \%\end{array}$ & $\begin{array}{c}0.56 \pm 1.1 \\
13 \%\end{array}$ \\
\hline $\begin{array}{l}\text { Insulin method } 2 \\
\text { Injection, \% } \\
\text { Pump, \% } \\
\text { Both, \% }\end{array}$ & $\begin{array}{c}62 \% \\
33 \% \\
5 \%\end{array}$ & $\begin{array}{l}55 \% \\
36 \% \\
9 \%\end{array}$ & $\begin{array}{c}54 \% \\
37 \% \\
9 \%\end{array}$ & $\begin{array}{c}55 \% \\
38 \% \\
7 \%\end{array}$ & $\begin{array}{c}55 \% \\
37 \% \\
8 \%\end{array}$ & 0.435 & $\begin{array}{c}55 \% \\
37 \% \\
8 \%\end{array}$ & $\begin{array}{c}64 \% \\
28 \% \\
8 \%\end{array}$ \\
\hline $\begin{array}{l}\text { Severe } \\
\text { Hypoglycemia }{ }^{3} \\
\text { No, \% } \\
\text { Yes all visits, \% } \\
\text { Yes not all visits, \% }\end{array}$ & $\begin{array}{c}95 \% \\
1 \% \\
4 \%\end{array}$ & $\begin{array}{c}88 \% \\
1 \% \\
11 \%\end{array}$ & $\begin{array}{c}90 \% \\
1 \% \\
9 \%\end{array}$ & $\begin{array}{c}88 \% \\
1 \% \\
11 \%\end{array}$ & $\begin{array}{c}86 \% \\
2 \% \\
12 \%\end{array}$ & 0.005 & $\begin{array}{c}89 \% \\
1 \% \\
10 \%\end{array}$ & $\begin{array}{l}89 \% \\
0.4 \% \\
11 \%\end{array}$ \\
\hline $\begin{array}{l}\text { Smoking habits }{ }^{4} \\
\text { No, \% } \\
\text { Yes all visits, \% } \\
\text { Yes not all visits, \% }\end{array}$ & $\begin{array}{c}70 \% \\
19 \% \\
11 \% \\
(n=115)\end{array}$ & $\begin{array}{c}85 \% \\
10 \% \\
5 \% \\
(n=292)\end{array}$ & $\begin{array}{c}92 \% \\
4 \% \\
4 \% \\
(n=1213)\end{array}$ & $\begin{array}{c}97 \% \\
1 \% \\
2 \% \\
(n=1560)\end{array}$ & $\begin{array}{c}98 \% \\
1 \% \\
1 \% \\
(n=383)\end{array}$ & $<0.001$ & $\begin{array}{c}93 \% \\
4 \% \\
3 \% \\
(n=3563)\end{array}$ & $\begin{array}{c}92 \% \\
5 \% \\
3 \% \\
(n=784)\end{array}$ \\
\hline $\begin{array}{l}\text { HbA1c, \% } \\
\text { (mmol/mol) } \\
\text { Mean } \pm S D\end{array}$ & $\begin{array}{l}8.8 \pm 1.5 \\
(72 \pm 16)\end{array}$ & $\begin{array}{l}8.6 \pm 1.4 \\
(70 \pm 16)\end{array}$ & $\begin{array}{l}8.2 \pm 1.1 \\
(66 \pm 12)\end{array}$ & $\begin{array}{l}7.9 \pm 1.0 \\
(63 \pm 11)\end{array}$ & $\begin{array}{l}7.7 \pm 1.0 \\
(60 \pm 11)\end{array}$ & $<0.001$ & $\begin{array}{l}8.1 \pm 1.2 \\
(65 \pm 13)\end{array}$ & $\begin{array}{l}8.1 \pm 1.1 \\
(65 \pm 12)\end{array}$ \\
\hline
\end{tabular}

Abbreviations: BMI-SDS, body mass index-standard deviation score; HbA1c, glycosylated hemoglobin A1c; PA, frequency of physical activity per week; PA0, none, PA1, less than once a week, PA2, 1-2 times per week, PA3, 3-5 times per week, and PA4, every day, PA unknown, this group includes all patients with no data on PA in SWEDIABKIDS.

${ }^{1}$ Chi-squared test was used to compare the different groups of physical activity for the following variables: gender, insulin method, hypoglycemia, and smoking habits. For the remaining variables we used one-way ANOVA. Hypoglycemia and smoking habits were tested on dichotomous scale (yes/no) due to small number.

${ }^{2}$ Data missing on insulin method for 78 (2\%) patients with PA known and $47(3 \%)$ patients with PA unknown. 
${ }^{3}$ Data missing on severe hypoglycemic episodes for $5(0.1 \%)$ patients with PA known and $6(0.3 \%)$ patients with PA unknown.

${ }^{4}$ Data missing on smoking habits for 1092 (23\%) patients with PA known and 1044 (57\%) patients with PA unknown. 
Table 2

Results of multiple regression analysis with HbA1c as dependent variable and $\beta$ are the linear association of mean PA.

\begin{tabular}{|c|c|c|c|}
\hline & $\begin{array}{c}\boldsymbol{\beta}^{1} \\
(95 \% \mathrm{Cl})\end{array}$ & $\mathbf{P}$ & Rsquare $^{2}$ \\
\hline Unadjusted $(n=4655)$ & $\begin{array}{c}-0.30 \\
(-0.34 \text { to }-0.26)\end{array}$ & $<0.001$ & $5 \%$ \\
\hline $\begin{array}{l}\text { Adjusted for gender and age } \\
(n=4655)\end{array}$ & $\begin{array}{c}-0.26 \\
(-0.29 \text { to }-0.22)\end{array}$ & $<0.001$ & $9 \%$ \\
\hline $\begin{array}{l}\text { Adjusted for gender, age, disease } \\
\text { duration, insulin dose, hypoglycemia } \\
\text { and number of visits }(n=4650)\end{array}$ & $\begin{array}{c}-0.21 \\
(-0.25 \text { to }-0.18)\end{array}$ & $<0.001$ & $19 \%$ \\
\hline
\end{tabular}

Abbreviations: CI, confidence interval; HbA1c, glycosylated hemoglobin A1c (NGSP).

Data subdivided as follows:

Age groups: 7-10, 11-14, 15-18.

Disease duration: $<5 \mathrm{y},>5 \mathrm{y}$.

Insulin dose: continuous scale.

Hypoglycemia: reported severe hypoglycemic at any episode v. no reported severe hypoglycemic episodes.

Smoking habits: reported smoking at any episode v. no reported smoking episodes.

${ }^{1}$ The $\beta$-coefficient indicates the mean unit the HbA1c level declines when mean PA increases with one unit.

${ }^{2}$ Percentage of the total variability of HbA1c explained by all factors in each model. 


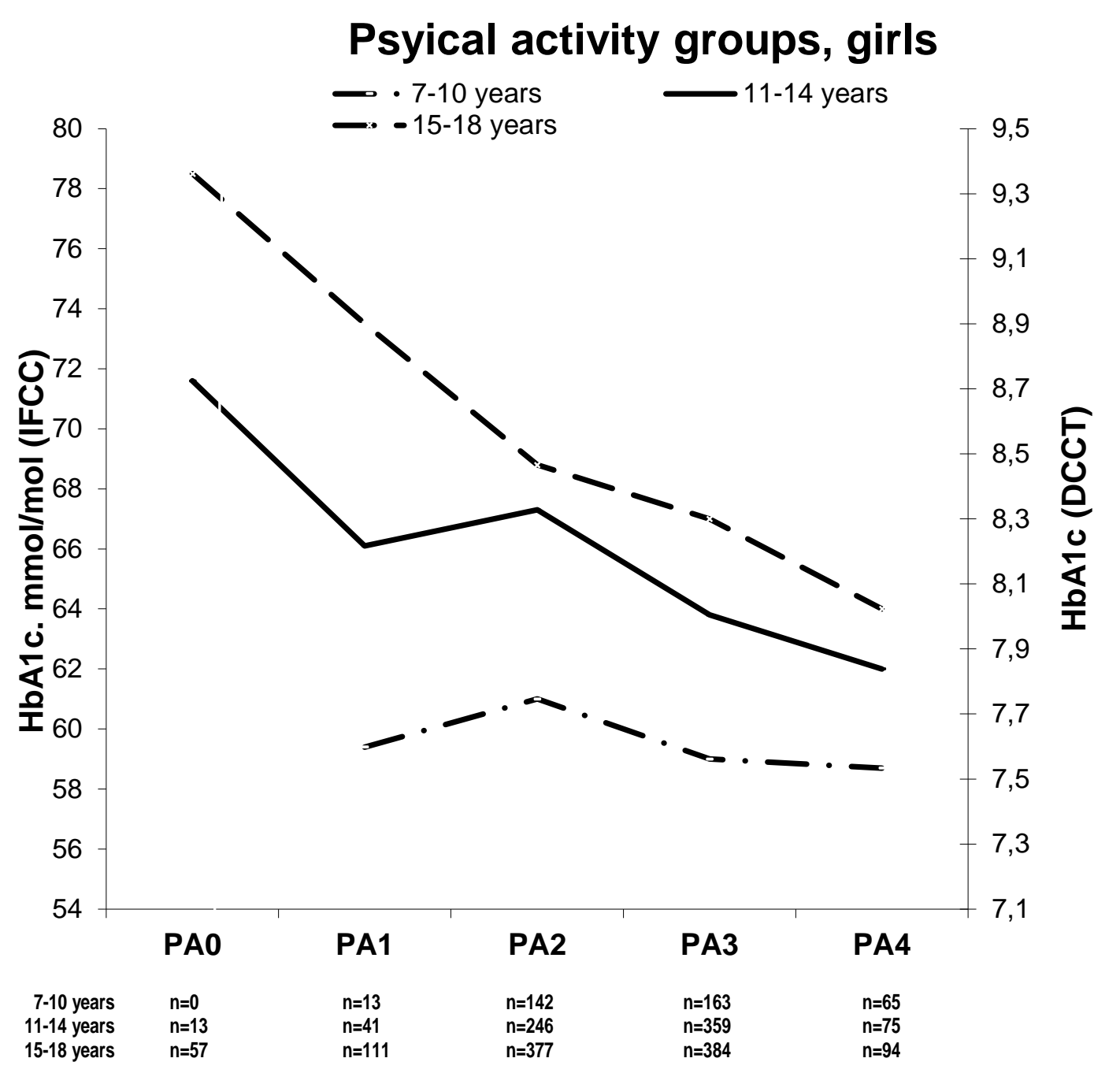




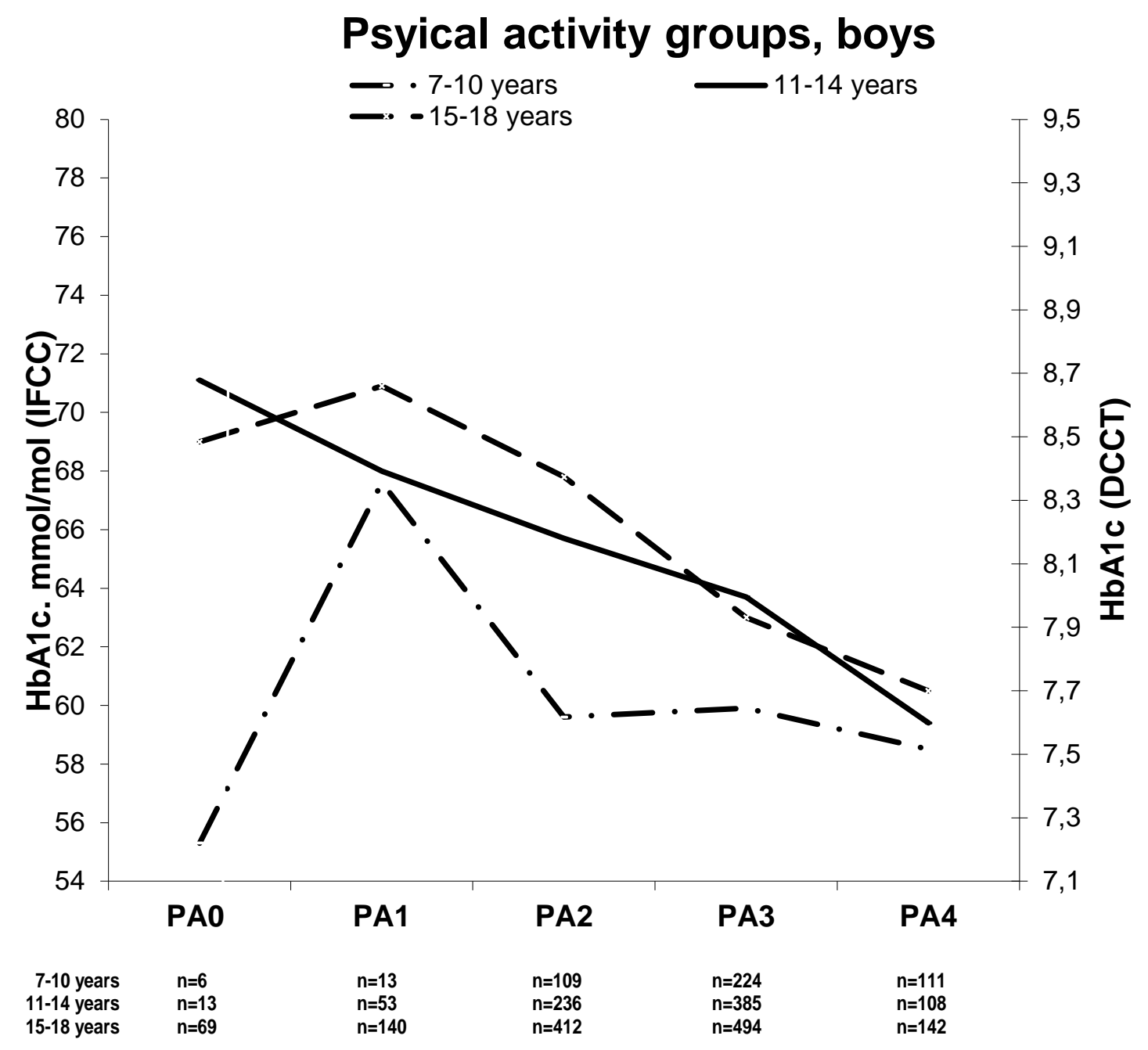




\section{Figure legend}

Figure 1. Mean HbA1c values in patients with type 1 diabetes stratified by age, gender, and frequency of physical activity.

Abbreviations: HbA1c, glycosylated hemoglobin A1c; PA, frequency of physical activity per week; PA0, none, PA1, less than once a week, PA2, 1-2 times per week, PA3, 3-5 times per week, and PA4, every day.

HbA1c values are presented in $\mathrm{mmol} / \mathrm{mol}$ according to the IFCC reference method and to the NGPS/DCCT reference method.

The number of patients in PA0 and PA1 is proportionally lower than in the other PA categories. 